\title{
Biodiverse cities: the nursery industry, homeowners, and neighborhood differences drive urban tree composition
}

\author{
Meghan L. Avolio, ${ }^{4}$ Diane E. Pataki, ${ }^{1}$ Tara L. E. Trammell,${ }^{2}$ and Joanna Endter-Wada ${ }^{3}$ \\ ${ }^{1}$ Department of Biology, University of Utah, Salt Lake City, Utah 84112 USA \\ ${ }^{2}$ Department of Plant and Soil Sciences, University of Delaware, Newark, Delaware 19716 USA \\ ${ }^{3}$ Department of Environment and Society, Utah State University, Logan, Utah 84322-5215 USA
}

\begin{abstract}
In arid and semiarid regions, where few if any trees are native, city trees are largely human planted. Societal factors such as resident preferences for tree traits, nursery offerings, and neighborhood characteristics are potentially key drivers of urban tree community composition and diversity, however, they remain critically understudied. We investigated patterns of urban tree structure in residential neighborhoods of the Salt Lake Valley, Utah, combining biological variables, such as neighborhood and plant nursery tree species and trait composition, and sociological data comprised of resident surveys and U.S. Census data. We sampled nine neighborhoods that varied in household income and age of homes. We found more tree species were offered in locally owned nurseries compared with mass merchandiser stores and yard trees at private residences were more diverse than public street trees in the same neighborhoods. There were significant differences among neighborhoods in street and yard tree composition. Newer neighborhoods differed from older neighborhoods in street tree species composition and trait diversity, while neighborhoods varying in affluence differed in yard tree composition. Species richness of yard trees was positively correlated with neighborhood household income, while species richness of street trees was negatively correlated with home age of neighborhood residences. Tree traits differed across neighborhoods of varying ages, suggesting different tree availability and preferences over time. Last, there was a positive correlation between resident preferences for tree attributes and the number of trees that had those attributes both in residential yards and in nursery offerings. Strong relationships between social variables and urban tree composition provides evidence that resident preferences and nursery offerings affect patterns of biodiversity in cities across Salt Lake Valley. These findings can be applied toward efforts to increase taxonomic and functional diversity of city trees in semiarid regions in ways that will also provide ecosystem services of most interest to residents.
\end{abstract}

Key words: city trees; ecosystem-service-based traits; horticultural products; plant nurseries; resident preferences; residential yards; socio-environmental research; street trees; tree diversity.

\section{INTRODUCTION}

Trees in cites are a ubiquitous landscape characteristic of urban areas throughout the United States, but vary in the degree to which they are planted (Dwyer et al. 2000). For example, in the semiarid city of Los Angeles, which was predominantly a shrubland prior to urbanization, $90 \%$ of trees are planted. In contrast, only $7 \%$ of trees are planted in the naturally forested city of Baltimore (Nowak 2012). These differences are influenced by climate and political-economic conditions. Los Angeles, for instance, does not have sufficient rainfall to support naturally forested ecosystems, but has very mild temperatures that allow a wide range of species to be imported from all over the world (Avolio et al., unpublished

Manuscript received 21 June 2017; revised 11 October 2017; accepted 26 October 2017. Corresponding Editor: Hannah L. Buckley.

${ }^{4}$ Present address: Department of Earth and Planetary Sciences, Johns Hopkins University, Baltimore, Maryland 21212 USA. E-mail: meghan.avolio@jhu.edu manuscript) and imported water that enables irrigation of trees (Kahrl 1983, Hundley 2001). Jenerette et al. (2016) suggested that climate, particularly freezing temperatures, limit tree diversity and plant functional traits in cooler climates, while in warmer, more mild climates, tree diversity and traits are shaped more by resident choices about which species to plant and maintain. In general, we currently have a relatively poor understanding of the factors that drive tree community composition and community assembly in cities, especially arid cities where the majority of trees are planted and water is a limiting resource.

We hypothesize that there are two important processes unique to urban ecosystems that affect urban plant community assembly: the offerings of local plant nurseries and preferences of land owners and managers for particular species and their associated traits. Most nurseries choose their inventory based, at least in part, on hardiness zone, which is determined by minimum temperatures (Daly et al. 2012). In addition to hardiness zone, plants' commercial viability is affected by many market-driven 
parameters (Safley and Wohlgenant 1995), including novelty and popularity, susceptibility to disease and pests, cost, ability to thrive in a given location, ease of propagation, and physical attributes (Townsley-Brascamp and Marr 1995, Pincetl et al. 2013). In cities, nurseries are the source of most cultivated plants (Day 1994), especially trees, which are the most common plant functional type sold by nurseries (Hall et al. 2011). The types of stores or nurseries where property owners and managers purchase their trees is most likely an important determinant of urban tree diversity; however, to our knowledge, this relationship is understudied and remains largely unquantified. For example, wealthier consumers tend to shop more at locally owned nurseries compared to mass merchandisers (Yue and Behe 2009), but it is unknown how differences in consumer behaviors might impact tree diversity among cities and neighborhoods.

Second, the preferences of people who purchase trees are also likely a key determinant of urban tree structure and composition and these people represent a diverse group of decision makers that includes individual homeowners, city planners and foresters, developers and construction firms, and various types of landscape professionals (landscape architects, landscape designers, nurseries, and horticulturalists; Hooper et al. 2008, Shakeel and Conway 2014, Avolio et al. 2015a, Conway and Vander Vecht 2015). For urban trees, the attributes that are desirable to these decision makers may not match plant functional traits typically used in ecological research. For example, residents purchasing trees for their yard are likely not as concerned with seed mass as they are with shading potential. Thus, urban plant research has started to use ecosystem-service-based traits (Pataki et al. 2013, Avolio et al. 2015a) or ecological amenity traits (Zhang and Jim 2014) that are more directly relevant to the preferences of urban residents purchasing and managing plants. For example, in southern California, Avolio et al. (2015b) found that people in hotter neighborhoods within a city had a greater preference for shade trees, and there were consequently more shade trees in those neighborhoods (Avolio et al. 2015a), even though trees are naturally less prevalent in desert regions of southern California and require irrigation. By focusing on traits valued by people planting urban trees, ecologist may be better able to both predict patterns of urban tree diversity and direct research efforts toward answering questions relevant to tree planting decision makers. Together, nursery offerings and peoples' preferences are potentially two key understudied drivers of city tree community structure and function.

Urban form and land-use type have been shown to be important determinants of city tree diversity and composition (Zipperer et al. 1997, Bourne and Conway 2013, Clarke et al. 2013). Within cities, there are both public trees, such as street trees planted in parking strips and medians, and private trees such as trees located on private property in residential yards. Residents and urban foresters most likely make decisions on species to plant based on different factors, which results in street and yard trees differing in traits and species composition (Jim 1993, Avolio et al. 2015a). Differences in physical and social characteristics of residential yards and preferences of residents among neighborhoods may also explain patterns of urban tree community structure. The age of homes (here termed "neighborhood home age") and household income (here termed "neighborhood income"), which are often correlated, have been shown to be related to urban tree diversity (Clarke et al. 2013) and canopy cover (Lowry et al. 2011). Older neighborhoods accumulate more trees over time, increasing both cover and diversity, similar to the process of natural succession where species accumulate over time (Anderson 2007). What underlies the relationship between neighborhood income and species richness, termed the "luxury effect" (Hope et al. 2003), is less clear. It is also uncertain whether neighborhoods that have similar social characteristics also have similar tree communities. The "ecology of prestige" theory (Grove et al. 2006) maintains that cultural norms and societal pressures result in neighborhood cohesion that influences the community structure and composition of vegetation. Accordingly, it is plausible that more affluent vs. less affluent neighborhoods could have different tree community assemblages, regardless of the number of species.

The focus of our research project was on studying urban trees in the Salt Lake Valley, a semiarid metropolitan area where we expected social drivers would be particularly important as the natural ecosystem is a shrubland and the majority of trees are planted and managed. The major land use category by acreage in the Salt Lake Valley metropolitan area is residential housing; thus, we focused on residents as the primary landscape decision makers for these areas. Our overall objective was to determine the role of local nurseries as plant suppliers and resident tree preferences in determining patterns of residential urban biodiversity. Sampling nine neighborhoods and popular local nurseries, we assessed (1) similarity between trees found in residential neighborhoods and local nursery offerings, (2) whether neighborhoods differed in species composition and ecosystem-service-based traits, (3) relative effects of average neighborhood income and housing age on attributes of urban trees, (4) resident preferences, buying, and planting decisions for yard trees, and (5) linkages between resident preferences and tree traits. We hypothesized that nurseries visited by residents would explain the neighborhood-income-plant-diversity relationship, where more affluent residents will be able to afford more trees and choose from a greater variety of nurseries. Additionally, we hypothesized that both nurseries' stock and resident preferences would drive patterns of urban biodiversity, resulting in more similar tree communities across neighborhoods in similar average household income and housing age categories. Finally, we hypothesized that since the majority of trees in Salt Lake Valley are planted and irrigated, attributes of the urban trees 
planted in residential neighborhoods would be closely linked to resident preferences for specific traits. Overall, our purpose was to increase understanding of residents' preferences for tree traits in order to help ecologists provide relevant scientific information and socially acceptable and adoptable recommendations to land managers in order to aid community decision making about ecologically healthy and sustainable city trees.

\section{Methods \\ Study site}

This study took place in Salt Lake County, Utah, which includes Salt Lake City and several other municipalities that comprise the Salt Lake City Metropolitan Statistical Area, hereafter called Salt Lake Valley (SLV). Currently, SLV has a population of just over 1 million people (U.S. Census Bureau, 2010). The ecoregion is Central Basin and Range (EPA Ecoregions III vegetation data, Ecoregions of North America; 2006) with dry basins dominated by sagebrush that are punctuated by forested mountain ranges. SLV is surrounded by the Wasatch Mountains to the east, the Oquirrh Mountains to the west, the Traverse Range to the south, and the Great Salt Lake to the north. The climate is continental, characterized by cold winters and hot dry summers. SLV receives $397 \mathrm{~mm}$ rainfall annually and the mean annual temperature is $11.5^{\circ} \mathrm{C}$ (PRISM Climate Group at Oregon State University, Corvallis, Oregon, USA). The region was settled by Europeans in the middle of the 1800s and has rapidly urbanized over the past four decades. The current extent of this metropolitan area is largely the valley floor (formerly sagebrush-dominated shrubland) with some neighborhoods extending into the foothills (formerly grassland and Quercus gambelii shrubland).

\section{Study design}

Neighborhood selection. - Neighborhoods were chosen from a typology developed for a larger project on human-environment interactions in the study region (Jackson-Smith et al. 2016). The larger study focused on 608 neighborhoods and used census blocks to define neighborhood boundaries. We narrowed the 608 neighborhoods to 315 by selecting for neighborhoods with the following characteristics: located below $1,524 \mathrm{~m}$ in elevation, received $<653 \mathrm{~mm}$ per year annual precipitation, had $<35 \%$ renter occupancy, consisted of more than $65 \%$ single family residences, and had more than 100 homes. We chose these parameters to limit the study to neighborhoods of sufficient size, in the valley floor having similar climates, and with primarily owner-occupied homes to increase the likelihood of interacting with the people who made landscape planting decisions. To span a range of neighborhood housing ages (minimum, built before 1939; maximum, built in 2005; median, built in 1976), we chose neighborhoods in three, temporally distinct categories: old (median year home built before 1939), middle (median year home built 1951-1970), and new (median year home built 1985-2005). Similarly, for neighborhood household income (minimum US\$33,000; maximum, US $\$ 178,000$; median, US\$68,000), we split the range into three categories: low (median household income <US\$45,000), medium (median household income US\$45-85,000), and high (median household income $>$ US\$85,000). These categories were chosen to capture the greatest range of variation in the data. We then chose one neighborhood that represented each possible unique combination of neighborhood home age and neighborhood income in order to avoid confounding effects between the two characteristics (Table 1). When multiple neighborhoods met our criteria, one was randomly chosen. In our experimental design, there were no replicates among the nine neighborhoods of any single home-age-income combination, but there were three replicates of each home age and income category. The final neighborhoods were broadly distributed across Salt Lake County (Appendix S1: Fig. S1).

Home selection. - In each of the nine selected neighborhoods, we chose five or six blocks to study. A block was defined as a continuous piece of land surrounded by road (Appendix S1: Fig. S2). We chose blocks that were regular shapes (e.g., rectangular) and had more than 15 homes on the block. We sent letters and sociological surveys to 15-20 randomly selected homes on each block. The last page of the survey asked if we could visit their home and collect plant data on their yard. For each neighborhood, we then selected three blocks to visit to collect tree data. In blocks where we did not get enough permissions via the survey, we walked door to door asking permission to sample a yard. For each block, we visited and sampled five yards, for a total of 15 yards per neighborhood and 135 yards across the Salt Lake Valley.

\section{Data collection}

Resident preferences surveys. - We conducted two surveys, one completed by mail and one completed in person during the yard sampling. The mail survey was designed to assess self-reported importance of various ecosystem services (e.g., provision of shade) and disservices (e.g., dropping of debris) of neighborhood trees (yard, street, and park trees) and is hereafter referred to as the neighborhood survey (Appendix S2: Document S1A). Surveys were mailed to 100 residents in each neighborhood (900 total). They were mailed twice, first in May 2014, and again to non-responders in October 2014 with a reminder post card sent a week later. The survey was designed to take approximately $15 \mathrm{~min}$ and included a self-addressed stamped return envelope. A total of 280 surveys were returned (Table 1) for a response rate of $31 \%$.

For each of the 135 sampled yards, we administered a second shorter survey to assess where residents 


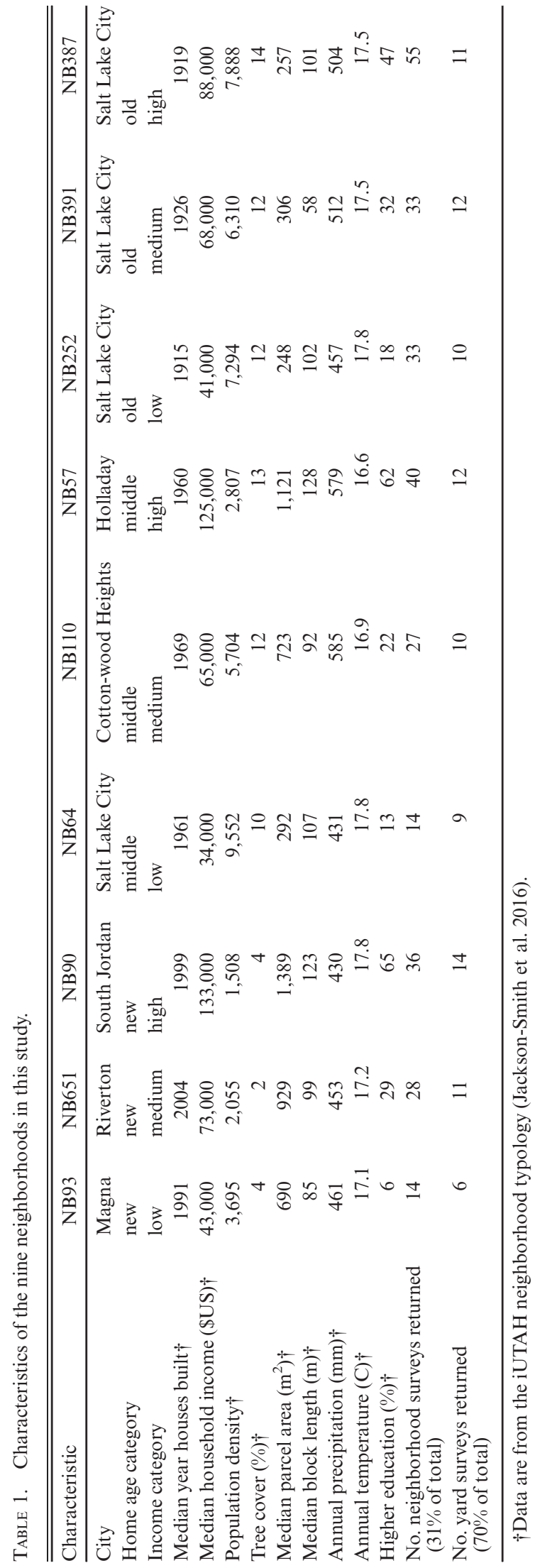

purchased trees and which attributes were important to them when choosing a tree for their yard. It was designed to take $5 \mathrm{~min}$ to complete and is hereafter referred to as the yard survey (Appendix S2: Document S2). If a resident was not present when we visited, we left the survey in their mailbox with a stamped selfaddressed return envelope. The response rate for this survey was $70 \%$ (Table 1 ).

Neighborhood tree data set. - We visited 135 residential locations selected for yard sampling over a three-week interval from mid-July to early August 2014. We recorded all trees in each yard and also walked the block perimeter and recorded all street trees in the parking strip (land between sidewalk and road). If a block did not have a parking strip, it was considered absent of street trees. This data set is hereafter referred to as the neighborhood tree data set. Most trees were identified to species ignoring cultivars. However, when cultivars were visually distinct (e.g., growth form or leaf color), we noted the phenotypic difference and counted the cultivar as a different species. For example, we noted when Norway maple (Acer platanoides) had red or green leaves, and counted these as separate "species," but did not differentiate between horticultural cultivars, because there are several red-leaf cultivars (e.g., Crimson King, Royal Red) and several greenleaf cultivars (e.g., Emerald Queen, Emerald Lustre) that are nearly impossible to distinguish. Our nine neighborhoods were located in five cities in the Salt Lake Valley that differed in street tree management policies, and whether city personnel or homeowners planted and maintained street trees. Street trees were planted and maintained by Salt Lake City in four neighborhoods and by the city of South Jordan in 1 neighborhood, while homeowners were required to maintain trees and plant trees if they desired street trees in Magna (1 neighborhood), Cottonwood Heights (1 neighborhood), Riverton (1 neighborhood) and Holladay (1 neighborhood). Further, for developments or neighborhoods with a home owner association (HOA), in the cities of Riverton, Cottonwood Heights, Holladay, and Magna, street trees were planted by the developer at time of building or residents were required to conform to HOA rules. In Holladay, most streets did not have street trees; street trees were common in Magna; in Cottonwood Heights, street trees were not common but some blocks did have them; and in Riverton, the sampled blocks were in developments and trees were likely planted by the developers as the trees were generally uniform in size, spaced regularly, and the overwhelming majority were flowering pear.

Nursery tree data set.-Over the course of a week in June 2015, we visited the six most popular nurseries in SLV, which were identified in the yard sampling survey. We visited three nursery sections of mass merchandisers, which were large, national home improvement retail stores that also sell trees (hereafter referred to as mass merchandisers). We also visited three independently 
TABLE 2. Explanation of ecosystem-service-based traits and their range of values.

\begin{tabular}{|c|c|}
\hline Ecosystem-service-based traits & Trait value range \\
\hline Longevity & 1-3 (1, short-lived; 3, long-lived) \\
\hline Leaf phenology & binary $(0$, deciduous or 1 , evergreen $)$ \\
\hline Growth rate & $1-3$ (1, slow growth rate; 3 , fast growth rate) \\
\hline Height & $1-3(1$, short; 3 , tall $)$ \\
\hline Shade tolerance & 1-3 (1, low shade tolerance; 3 , high shade tolerance) \\
\hline Aromatic & binary $(0$, not aromatic; 1 , aromatic $)$ \\
\hline Native & binary $(0$, not native; 1 , native $)$ \\
\hline Good for power lines & binary $(0$, not good for power lines; 1 , good for power lines) \\
\hline Service: Flowering & $0-2$ ( 0 , no flowers or inconspicuous flowers; 1 , flower; 2 , large very showy flowers) \\
\hline Service: Aesthetically pleasing bark & binary $(0$, bark not pleasing; 1 , bark pleasing) \\
\hline Service: Aesthetically pleasing foliage & binary ( 0 , foliage not pleasing; 1 , foliage pleasing) \\
\hline Service: Fall color & binary $(0$, no fall color; 1 , leaves turn a color in the fall $)$ \\
\hline Service: Fruit showiness & binary $(0$, fruit not showy; 1 , fruit showy) \\
\hline Service: Beauty & 0-6 (sum of flowering, bark, foliage, fall color, and fruit showiness) \\
\hline Service: Fruiting & binary $(0$, no edible fruit; 1 , provides edible fruit $)$ \\
\hline Service: Shade provision & $1-3$ (1, low shade; 3 , high shade) \\
\hline Service: Drought tolerance & $1-3$ (1, not drought tolerant 3 , high drought tolerance) \\
\hline Disservice: Allergen & $0-3(0$, not a known allergen; 3 , bad allergen $)$ \\
\hline Disservice: Pest infestations & 1-3 (1, few known pest problems; 3 , several known pest problems \\
\hline Disservice: Water requirement & $0-3$ (0, no supplemental irrigation required; 3 , heavy watering requirement) \\
\hline Disservice: Damaging roots & $1-3$ (1, roots not damaging; 3 , roots very damaging) \\
\hline Disservice: Drop litter & $\begin{array}{l}\text { binary ( } 0 \text {, does not drop a lot of debris/litter; } 1 \text {, drops a copious amount of debris or litter). } \\
\text { Note: dropping of leaves by deciduous trees in the fall did not count as a } 1 \text {, as most trees } \\
\text { do this. }\end{array}$ \\
\hline Disservice: Poisonous & binary $(0$, not poisonous; 1 , poisonous $)$ \\
\hline
\end{tabular}

owned local nurseries and garden centers (hereafter referred to as locally owned nurseries). At each store, we recorded all tree species offered for sale. For each species, we counted the number of trees for sale and the retail price (which varied with tree size in addition to species type). We did not distinguish among cultivars unless the cultivars had very different visual characteristics in order to use the same criteria for identification used in the neighborhood tree sampling.

\section{Ecosystem-service-based traits}

We used an ecosystem-service-based trait classification (Pataki et al. 2013, Avolio et al. 2015b) that was developed to identify plant traits that provided desired services to urban residents (Avolio et al. 2015a); thus, the emphasis was more on cultural services over regulating ecosystem services. For the species identified in this study, trait classifications were determined from the following sources: Utah State University Cooperative Extension's Tree Browser, California Polytechnic State University's Urban Forest Ecosystems Institute database, and Sunset's Western Garden Book (Brenzel 2001; data available online). ${ }^{5,6}$ We examined several traits based on visual or aesthetic characteristics that are identifiable to most residents (i.e., flowering, aesthetically

\footnotetext{
${ }^{5} \mathrm{http} / / /$ www.treebrowser.org/

${ }^{6} \mathrm{http} / / /$ selectree.calpoly.edu/
}

pleasing bark or foliage, fall color, and fruit showiness) and created categorical variables to describe them (Table 2). For example, flowering had three categories: 0 for species that did not flower (e.g., coniferous trees) or species with inconspicuous flowers (e.g., maple trees); 1 for trees whose flowers are visible and conspicuous (e.g., apple trees); and 2 for trees that had large showy flowers (e.g., magnolia trees). We used two categories of fruit showiness that depended on whether the fruit or berries were very visible or not. Overall, we derived a general category of "beauty," which was the sum of the flowering, fall color, showy fruit, pleasing bark and pleasing foliage categories. We also quantified traits based on provision of other functional services for people, including: fruiting, provision of shade, and drought tolerance, all of which were from Utah State University Cooperative Extension or California Polytechnic State University's Urban Forest Ecosystems Institute databases (see footnotes 5 and 6). Additionally, we quantified disservices of trees including damaging roots (the extent to which roots could damage the yard and sidewalk), drop litter (trees that dropped fruit, large pods, or other nonleaf material), allergen (from the Pollen Library; data available online), ${ }^{7}$ pest infestations (depending on how many pests were known to be a nuisance for a given species, which was listed in California Polytechnic State University's Urban Forest Ecosystems Institute

\footnotetext{
${ }^{7}$ http://www.pollenlibrary.com
} 
database), poisonous, and water requirement (from Western Garden Book). Last, we quantified additional ecosystem-service-based traits of trees that are neither generally a service or disservice but that influence the suitability of tree species for specific locations or uses; these traits included growth rate, mature height, shade tolerance, longevity, leaf phenology, native, aromatic, and good for power lines, all of which were from Utah State University Cooperative Extension or California Polytechnic State University's Urban Forest Ecosystems Institute databases.

\section{Data analysis}

All analyses were conducted in $\mathrm{R}$ (Version 3.3.2; R Core Development Team, Vienna, Austria) and statistical significance was considered at $\alpha=0.05$. A full list of all the variables measured or included in this study can be found in Table 3 .

Nursery data.-We used one-way ANOVA to compare the number of species offered and cost of trees between mass merchandiser stores and locally owned nurseries.

Neighborhood tree composition.-We used the metaMDS in the vegan package (Oksanen et al. 2017) for non-dimensional multivariate scaling to compare whether neighborhoods and tree locations (street vs. yard) had different species composition or traits. For the species data, we calculated the abundance of each species for each block (street trees) or residential parcel (yard trees) and used Bray-Curtis dissimilarity to determine how similar neighborhoods were to one another. For the trait data, we calculated the mean of each trait for each block or yard and used Bray-Curtis dissimilarity to determine how similar neighborhoods were to one another. We used the adonis function to perform permutation multivariate ANOVA to test whether neighborhoods had different centroid means and the betadisper function to perform multivariate homogeneity of group dispersions to test whether neighborhoods had different dispersion around centroid means. Within a neighborhood, we used individual residential properties as the replicate for the yard trees $(n=15)$ and the block as the replicate for street trees $(n=3)$. We also conducted similar multivariate analyses to see if there were differences between street and yard trees when all trees were aggregated up to the neighborhood $(n=9)$. To determine the relationship between distance between neighborhoods $(\mathrm{km})$ and tree community similarity based on species abundance data, we performed Mantel correlations using the Vegan package. Geographic distances were

TABLE 3. Types of variables and data collected.

\begin{tabular}{|c|c|}
\hline Variable measured & Description of the variable \\
\hline \multicolumn{2}{|l|}{ Neighborhood characteristics } \\
\hline Income & median household income \\
\hline Home age & median year homes were built \\
\hline Education & percent of adults with a bachelor's education or higher \\
\hline Population density & number of people in a given area \\
\hline Tree cover & average percent tree cover \\
\hline Median parcel area & median size of a parcel $\left(\mathrm{m}^{2}\right)$ \\
\hline Median block length & median length of a block (m) \\
\hline Precipitation & mean annual precipitation (mm) \\
\hline Temperature & mean annual temperature $\left({ }^{\circ} \mathrm{C}\right)$ \\
\hline Elevation & mean elevation \\
\hline \multicolumn{2}{|l|}{ Tree data } \\
\hline Number of trees & number of trees in a yard, block, neighborhood, or nursery \\
\hline Species richness & number of tree species in a yard, block, neighborhood, or nursery \\
\hline Yard tree density & number of trees in a yard per acre \\
\hline Yard tree richness density & number of tree species in a yard per acre \\
\hline Species composition & abundance of all species for a yard, block, or neighborhood \\
\hline Ecosystem-service-based traits & average trait value (across all trees) for a yard, block, neighborhood \\
\hline No. trees with trait & $\begin{array}{l}\text { the summed number of trees with the trait of interest for a yard, Salt Lake Valley } \\
\text { or nursery location }\end{array}$ \\
\hline \multicolumn{2}{|r|}{ (1) } \\
\hline Categorical reasons for removing a tree & percent of residents who reported a given reason \\
\hline Favorite genus & number of residents who reported a specific genus \\
\hline Categorical reasons for favorite genus & percent of residents who reported a given reason \\
\hline Ecosystem service and disservice traits & $\begin{array}{l}\text { importance of trait to resident ( } 0 \text {, not important; } 1 \text {, somewhat unimportant; } \\
2 \text {, somewhat important; } 3 \text {, important })\end{array}$ \\
\hline Tree attributes & $\begin{array}{l}\text { importance of tree attribute to resident ( } 0 \text {, not important; } 1 \text {, somewhat unimportant; } \\
2 \text {, somewhat important; } 3 \text {, important })\end{array}$ \\
\hline
\end{tabular}

Note: Neighborhood characteristics used in this study, which follow Jackson-Smith et al. (2016), are at the census block level. 
calculated in $\mathrm{R}$ with the distm function in the geosphere package (Hijmans et al. 2017) using the distcosine function.

Neighborhood characteristics and urban tree composition. - We calculated neighborhood tree species richness and number of trees by aggregating all residential blocks and yards up to the neighborhood level for regression analyses. We utilized multiple regression to assess the role of possible independent variables from the neighborhood characteristics in Table 3 (tree cover, income, home age, education, elevation, precipitation, temperature, median parcel area, and median block length). The overall model with the lowest AIC scores (income, home age, and elevation) is presented here. We include a table in the supplemental materials of how the other neighborhood characteristic variables (tree cover, education, precipitation, temperature, median parcel area, and median block length) were correlated with aspects of the urban tree community composition and the three independent variables included in the final model (Appendix S3: Table S1). To study relationships among neighborhood income, home age, or elevation on tree community composition, we performed forward and backward stepwise multiple regressions using the MASS package (Ripley et al. 2017). We used the relaimpo package to calculate partial regression coefficients (Groemping and Matthias 2013). The three-explanatory neighborhood characteristic variables (income, home age, and elevation) were not correlated with one another (Appendix S3: Fig. S1).

Due to the nature of the experimental design, we separately evaluated the effects of neighborhood home age and neighborhood income. To study how blocks and yards differed in tree species richness across neighborhoods, we used one-way ANOVA separately for neighborhood income and neighborhood home age with street trees (block as the replicate) and yard trees (residential parcel as the replicate). For ecosystem-servicebased traits, we used the average trait value for each neighborhood. To study the differences of ecosystemservice-based traits between tree type (street or yard) and neighborhood home age or income we used twoway ANOVAs.

Resident preferences.-We used a 4-point Likert scale from 0 (not important) to 3 (important) to rank the importance of traits residents reported when choosing a tree to plant on their property (from the yard survey) and the importance of tree services and disservices (from the neighborhood survey). In the neighborhood survey we aslo asked residents whether they removed a tree and why as well as which tree in their yard was their favorite and why and coded the responses.

Linking preferences to traits.-To link these resident preferences to measured traits in yards and nurseries, we focused on traits that were easily matched to preferences. For example, residents reported whether they chose a tree based on if it was deciduous or not, which is a tree trait that can be represented by a categorical variable. We determined whether a tree had the desired trait or not, by coding it 1 (present) or 0 (absent) and summed across all recorded yard or nursery trees. For all yard and nursery trees, we determined that a species had a particular trait if it fell into the highest respective category, e.g., the highest shading potential (3), the lowest water requirement $(0)$, and visible and recognizable flowers $(>1)$. For the other binary variables, we included deciduous or evergreen traits, provision of edible fruit, a noticeable aroma, fall foliar display, and low maintenance requirement (i.e., not dropping debris). From the neighborhood survey, we additionally included nondamaging roots $(<2)$ and trees that were non-allergenic. We also included a measure of beauty, which we calculated as a tree with a value $>2$ to be counted present for yard trees to be counted and $>1$ to be counted for nursery trees. For the nursery tree data set, we did not have trait information on pleasing foliage or bark because many species were not included in the USU's Cooperative Extension's Tree Browser, so the threshold for the additive beauty category was reduced. We performed Pearson's correlations between the self-reported importance of a tree attribute and the overall number of yard or nursery trees that had that trait. We performed similar analyses within yards, between the self-reported importance for residents of a specific trait and the average value of that trait category in their yard. Finally, we performed correlations between the number of respondents reporting a genus as their favorite and the number of recorded yard and nursery trees of that genus.

\section{Results}

\section{Comparing urban tree composition with retail nursery offerings}

We recorded 859 street trees across 27 neighborhood blocks, 1,151 yard trees across 135 residential parcels, 11,190 trees in three locally owned retail nurseries, and 2,250 trees in three mass merchandiser stores. These trees represented 148 species growing in our study neighborhoods and 262 species offered for sale. The majority of trees in residential neighborhoods and in nurseries were nonnative, with $11 \%$ native tree species growing in the neighborhoods and 9\% native species offered for sale. The species pool of yard trees (132 species) was much greater than that of street trees (62 species). The species pool of locally owned nurseries (219 species) was much greater than that of mass merchandisers ( 80 species). There was greater evenness of yard tree species (similar relative abundance of species), and much greater dominance of certain species in the street trees (Fig. 1). A similar pattern was found for locally owned nurseries compared to mass merchandisers (Fig. 1). Additionally, locally owned nurseries offered, on average, three times more species $(143 \pm 10$ [mean $\pm 1 \mathrm{SE}])$ than national 

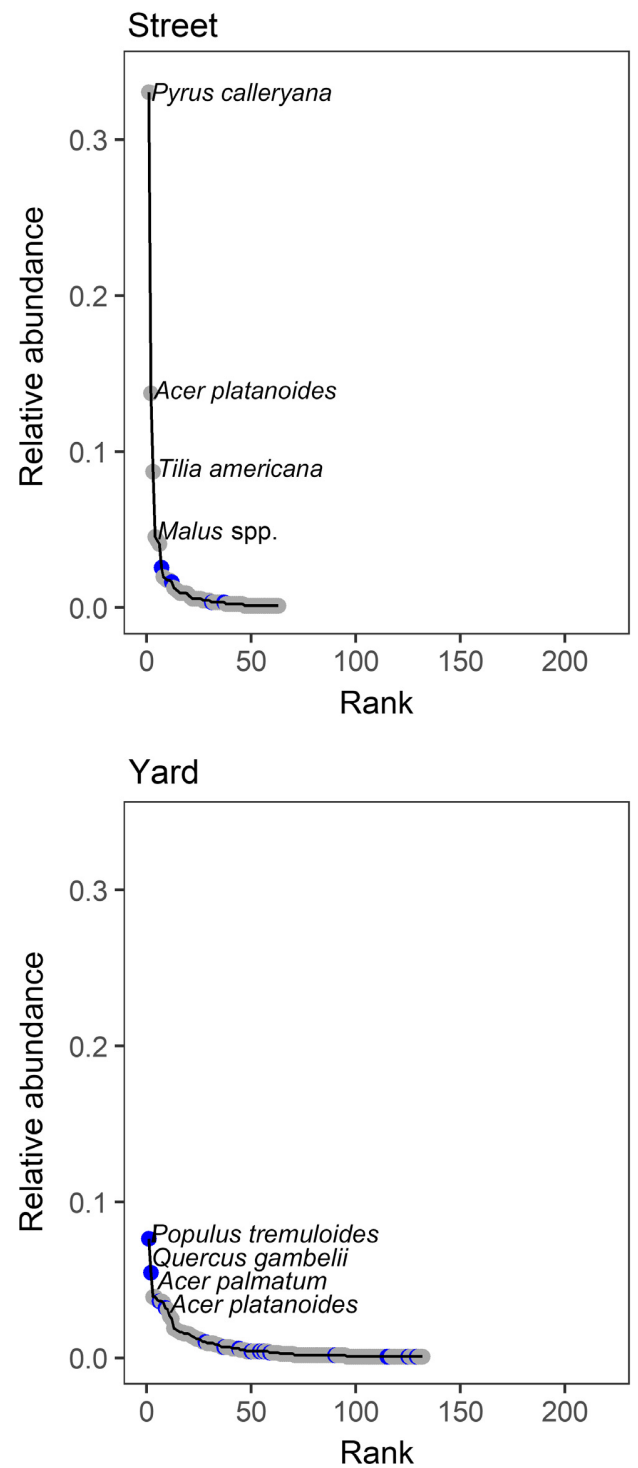

Mass merchandiser

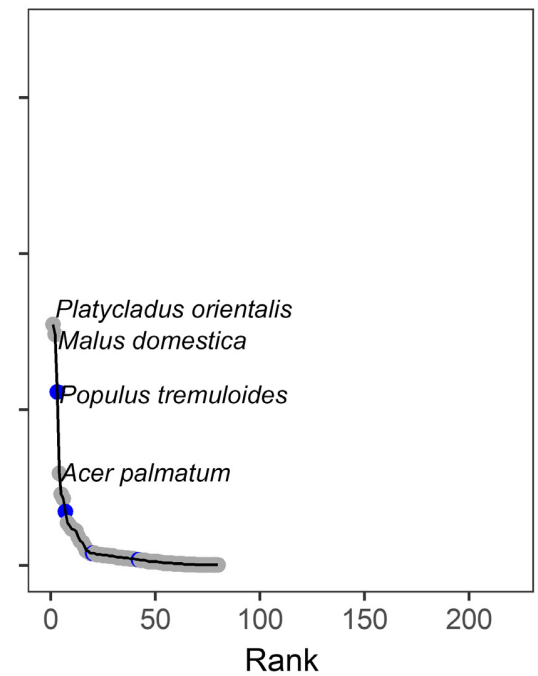

Locally owned nursery

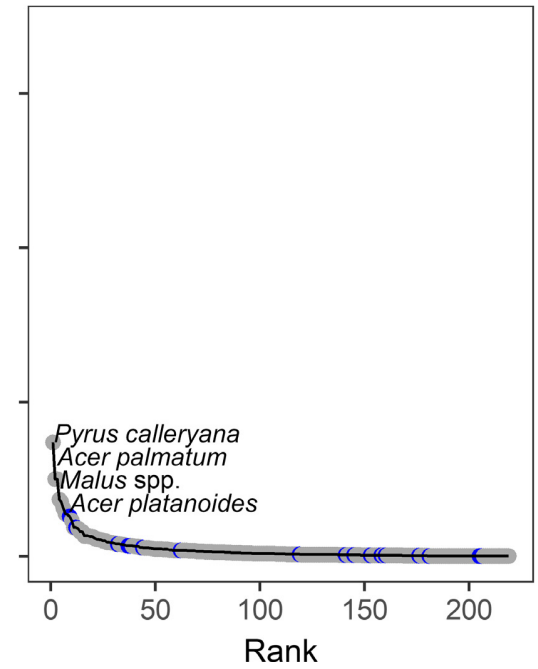

FIG. 1. Rank abundance curves of trees found in Salt Lake Valley (street and yard) and nurseries (mass merchandisers and locally owned nurseries), showing the relative abundance of a species vs. its rank. The four most common species in each panel are labeled.

mass merchandiser stores ( $46 \pm 10$ species; $F_{1,4}=48.01$, $P=0.002)$, and overall trees were, on average, much less expensive in mass merchandiser stores (US\$73 \pm US\$8) compared with locally owned nurseries (US\$173 \pm US $\left.\$ 13 ; F_{1,4}=42.7, P=0.003\right)$. The same relationship held when looking at the minimum cost of a species at a nursery, where the minimum cost of a species in a mass merchandiser was US\$65 \pm US\$5 while the minimum cost at locally owned nurseries was US\$152 \pm US\$4 $\left(F_{1,4}=\right.$ $170, P=<0.001$ ).

Twenty-three species $(16 \%)$ recorded in SLV were not found in the stores. Of these, 15 were most likely species that were misidentified in the field but were later identified in nurseries after the yard sampling had occurred. Additionally, three species were invasive (Ulmus pumila,
Ailanthus altissima, and Elaeagnus angustifolia) and were not part of the nursery trade, and five were simply not found for sale in the nurseries we inventoried (they may have been available in other Utah nurseries, or may have been acquired under unique circumstances by those who planted them). Overall, there was a strong correlation between the abundance of each observed tree species in streets and yards and abundance of each species found in the stores $(r=0.705 ; P<0.001$; Appendix S4: Fig. S1).

\section{Neighborhood tree composition}

Across the study neighborhoods, street and yard tree communities differed in both composition of species $\left(F_{1,16}=4.11 ; \quad P=0.001\right)$ and ecosystem-service-based 


\section{Species composition}

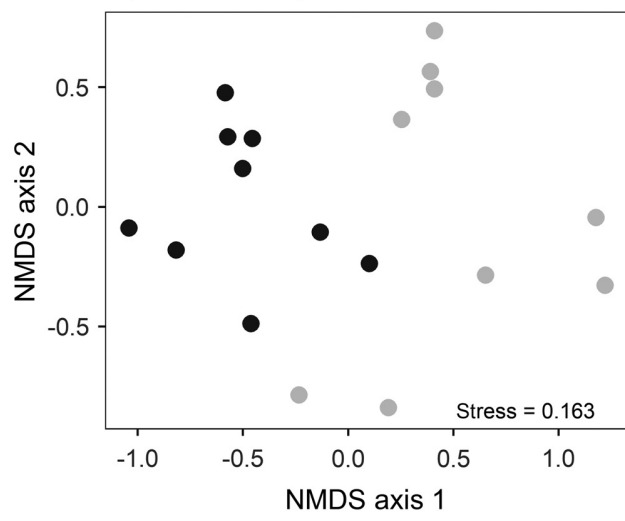

Ecosystem-service-based traits

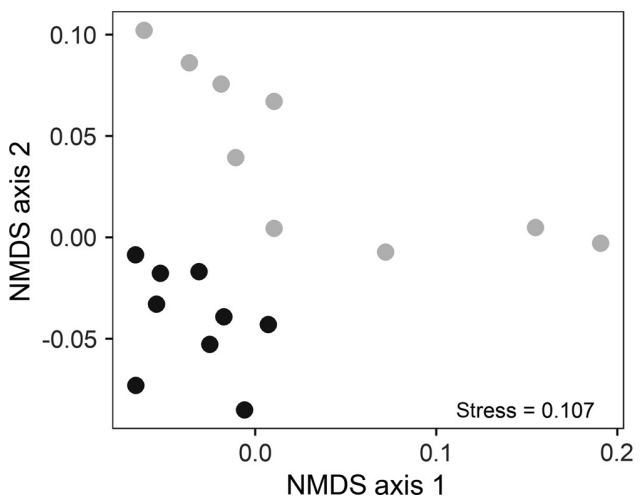

FIG. 2. Comparisons of species composition and traits of street and yard trees. Each point denotes a neighborhood $(n=9)$.

traits $\left(F_{1,16}=6.31, P=0.001\right.$; Fig. 2$)$. While street and yard trees showed the same degree of dispersion around the centroid in terms of species composition $\left(F_{1,16}=3.73, P=0.057\right)$, there was greater dispersion in the traits of street trees among neighborhoods compared with yard trees $\left(F_{1,16}=11.07, P=0.005\right.$; Fig. 2$)$. For

TABLE 4. Species composition and aggregate trait differences of street and yard trees across neighborhoods.

\begin{tabular}{lccccr}
\hline \hline & \multicolumn{2}{c}{$\begin{array}{c}\text { Difference in } \\
\text { means }\end{array}$} & & \multicolumn{2}{c}{$\begin{array}{c}\text { Difference in } \\
\text { dispersion }\end{array}$} \\
\cline { 2 - 3 } Tree type & $F$ & $P$ & & $F$ & $P$ \\
\hline $\begin{array}{l}\text { Species composition } \\
\quad \text { Street }\end{array}$ & 2.94 & 0.001 & & 8.04 & 0.002 \\
$\quad$ Yard & 1.75 & 0.001 & & 1.77 & 0.091 \\
Aggregate traits & & & & \\
$\quad$ Street & 4.82 & 0.001 & & 4.09 & 0.007 \\
$\quad$ Yard & 1.79 & 0.003 & & 3.70 & 0.001 \\
\hline
\end{tabular}

Note: For the street trees, the unit of replication was the block $(n=3)$ and, for yard trees, it was the residence $(n=5)$. $F$-value degrees of freedom were 8,17 for the street tree models and 8,118 for the yard tree models. both street and yard tree communities, neighborhoods differed in both species composition and traits (Table 4, Fig. 3). For street trees, neighborhoods appeared to group by home age, in that younger neighborhoods had different species composition and traits compared with middle and older neighborhoods, which were more similar to each other (Fig. 3). For yard trees, no clear groupings could be identified by neighborhood characteristics (Fig. 3). Neighborhoods differed in their dispersion (size of error bars) for both species and traits of street trees (Table 4, Fig. 3), and for traits but not species of yard trees (Table 4, Fig. 3). Lastly, there was evidence of spatial auto-correlation for both street trees $(r=0.661$, $P=0.002)$ and yard trees $(r=0.493, P=0.009)$, where neighborhoods that were closer together spatially had more similar tree communities (Appendix S5: Fig. S1).

\section{Neighborhood characteristics and urban tree composition}

Neighborhood income was a strong determinant of yard tree richness and total number of trees (Table 5, Fig. 4), where higher income neighborhoods had greater number of trees and higher tree species richness. There were also more trees in older neighborhoods (data not shown; Table 5). Neighborhood income, neighborhood home age, and elevation did not explain variation in number of street trees (Table 5), but neighborhood home age strongly affected street tree species richness, where older neighborhoods had greater street tree richness (Table 5, Fig. 5). The tree density of residential yards was positively correlated with neighborhood home age and elevation, but not neighborhood income (Table 5).

Neighborhood blocks had a similar number of street trees regardless of neighborhood home age $\left(F_{2,23}=2.54\right.$; $P=0.101)$ or neighborhood income $\left(F_{2,23}=0.98\right.$, $P=0.391)$, and similar species richness regardless of income $\left(F_{2,23}=0.74 ; P=0.929\right)$. Streets in older neighborhoods had greater tree species richness $(14.0 \pm 1.5$ species) than newer ( $4.3 \pm 0.8$ species) or middle-aged $(7.0 \pm 1.6$ species $)$ neighborhoods $\left(F_{2,23}=14.03\right.$; $P<0.001)$. Residential yards had the same number of trees regardless of neighborhood home age $\left(F_{2,124}=1.998, P=0.140\right)$, but high income $(11.7 \pm 1.2$ trees) and middle income (9.8 \pm 1.1 trees) yards had more trees than low income yards $(5.2 \pm 0.9$ trees; $\left.F_{2,124}=9.14, P<0.001\right)$. High income yards also had greater species richness $(6.8 \pm 0.6$ species $)$, followed by middle income yards $(5.3 \pm 0.4$ species $)$, and low income yards had the lowest species richness $(3.4 \pm 0.4$ species; $\left.F_{2,124}=12.8, P<0.001\right)$. Last, middle-aged residential yards had greater species richness $(6.4 \pm 0.6$ species) compared with older residential yards $(4.7 \pm 0.5$ species $)$, but not new residential yards ( $4.8 \pm 0.4$ species; $F_{2,124}=3.70, P=0.027$ ).

There was no statistically significant effect of neighborhood income on any ecosystem-service-based traits (data not shown) but there were several interactions between neighborhood home age and tree location (yard 
Street species composition

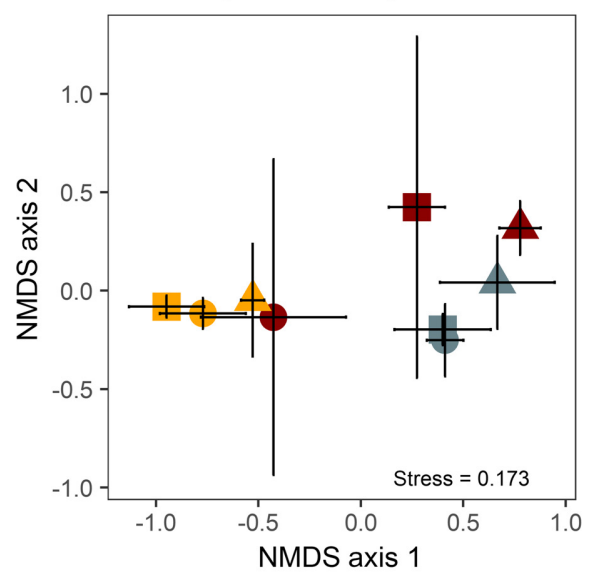

Yard species composition

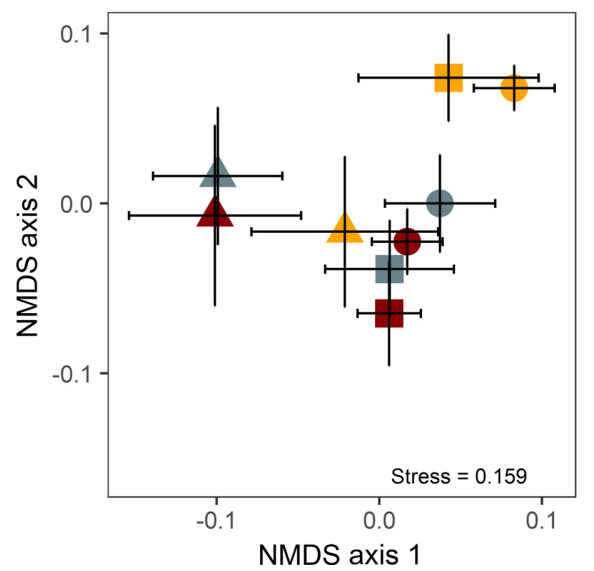

Street traits
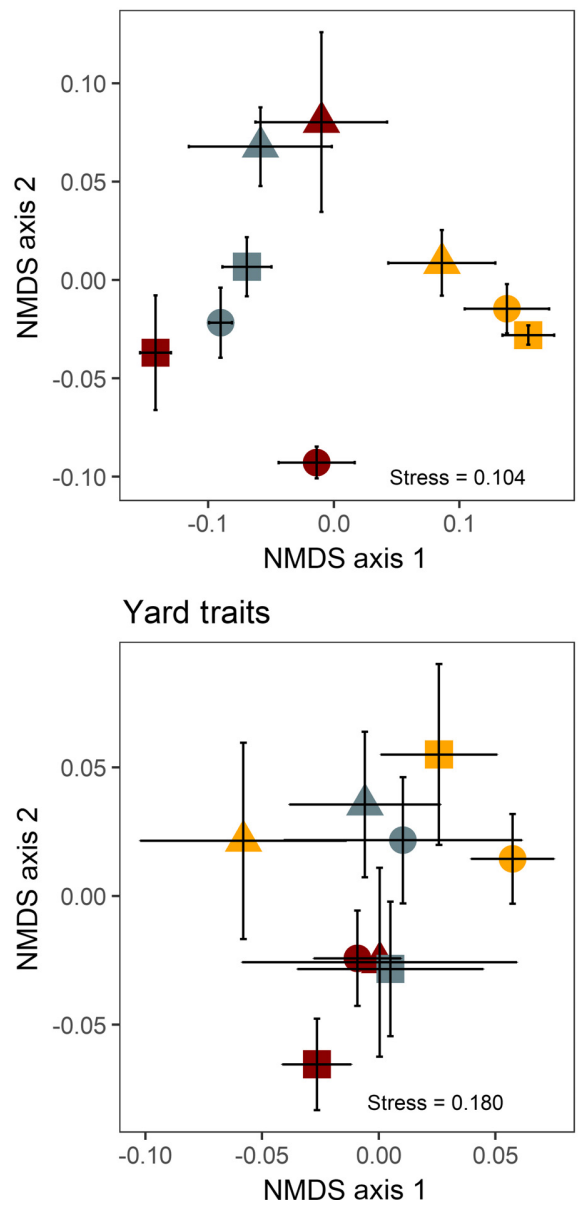

Neighbhorhood income

$\Delta$ Low Middle

Neighbhorhood home age

Young

Middle

Old

FIG. 3. Composition of species and trait differences across neighborhoods for street and yard trees. The average nonmetric multidimensional scaling (NMDS) values ( \pm SE) of each neighborhood is shown $(n=3$ for street trees and $n=15$ for yard trees). The location of the point approximates the centroid mean, and the size of the error bars shows how much replicates vary, an indication of dispersion around the mean. The income of a neighborhood is delineated by shape and the home age of a neighborhood is delineated by gray-scale color.

or street) for traits (Table 6). In middle-aged neighborhoods, street trees had a higher proportion of fast growing species (growth rate) than yard trees (Fig. 5). In older neighborhoods, street trees were taller and required more water than yard trees (Fig. 5). In young neighborhoods, more street trees had showy flowers and were more drought tolerant than yard trees (Fig. 5), most likely driven by flowering pear trees. Overall, tree beauty was higher in younger neighborhoods compared with middle-aged and older neighborhoods.

TABLE 5. Relationships between metrics of city tree diversity structure and composition with environmental (elevation) and social (neighborhood income and neighborhood home age) factors.

\begin{tabular}{llcccc}
\hline \hline Tree type & City tree metric & Model adjusted $R^{2} \dagger$ & Elevation & Neighborhood income & Neighborhood home age \\
\hline Yard & Number of trees & $0.781^{*}(60.94)$ & 0.085 & $0.673^{* *}$ & $0.104^{*}$ \\
Yard & Species richness & $0.758^{* *}(37.47)$ & & $0.773^{* *}$ & 0.045 \\
Yard & Tree density & $0.836^{* *}(38.21)$ & $0.189^{*}$ & 0.079 & $0.629^{* *}$ \\
Yard & Richness density & $0.859^{* *}(23.09)$ & $0.171^{*}$ & 0.081 & $0.660^{* *}$ \\
Street & Number of trees & n.s. & & & $0.692^{* *}$ \\
Street & Species richness & $0.648^{* *}(34.07)$ & & & \\
\hline
\end{tabular}

Notes: If an explanatory factor was not included in the final model, the cell is left blank. Otherwise, relative importance of the factor is reported.

$* P<0.05, * * P<0.01$.

$\dagger$ Values in parentheses are the Akaike information criterion (AIC). 

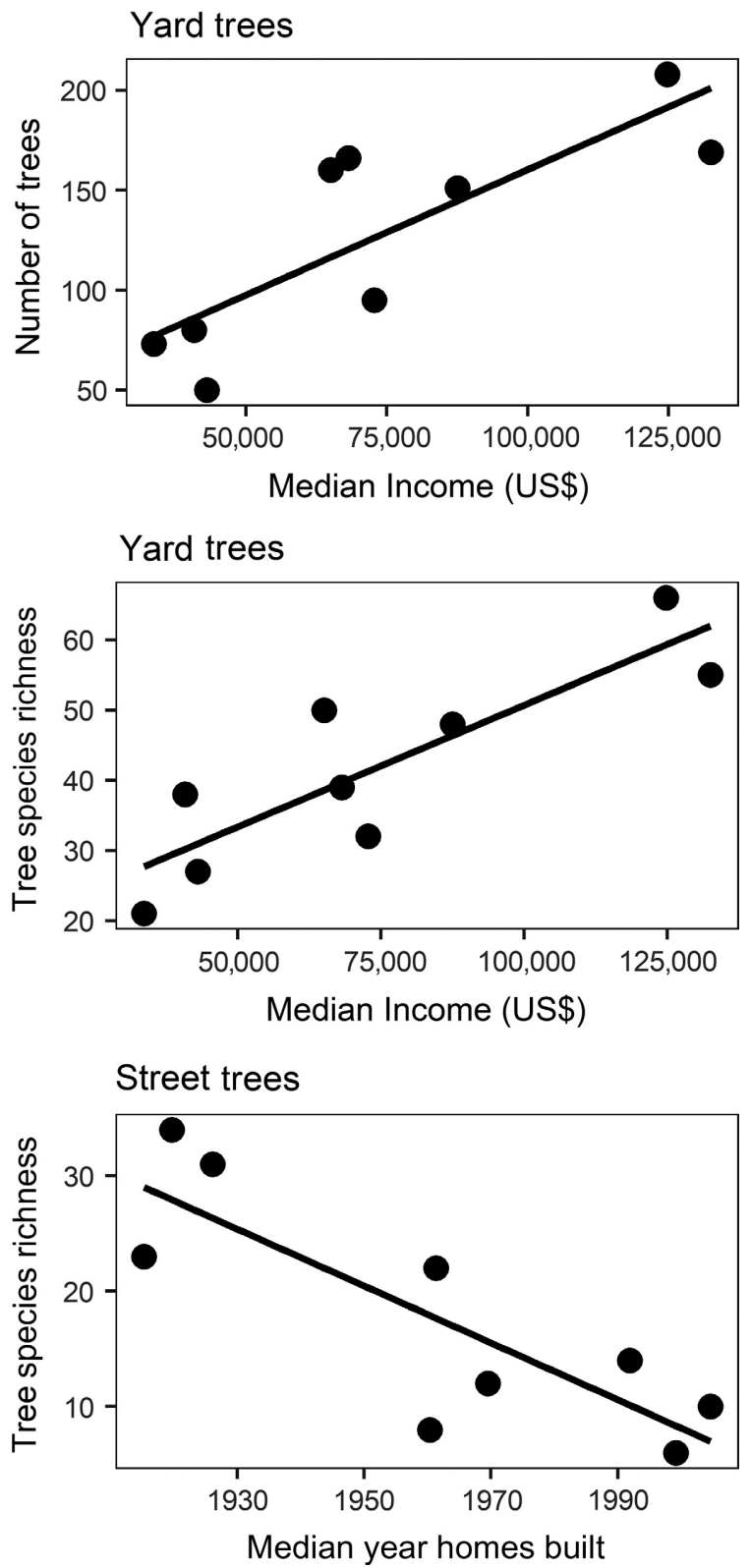

FIG. 4. Relationships between tree number and diversity and social variables. $R^{2}$ and $P$ values are found in Table 3 .

\section{Resident preferences}

We received 280 neighborhood surveys rating the importance of ecosystem services and disservices of trees in neighborhoods and 95 yard surveys covering attributes used to select trees for planting. The majority of respondents $(78 \%)$ reported planting a tree in their yard at some point. Of those residents that planted at least one tree in their yard, $12 \%$ said a tree was acquired from acquaintances and $92 \%$ said trees were bought from stores (actions of residents who did both are included in these percentages). Residents were also asked which stores they visited to purchase trees. Higher income residents tended to shop at locally owned nurseries compared with lower income residents $\left(F_{2,66}=2.64\right.$, $P=0.08)$, but all residents shopped at an equal number of national chain stores $\left(F_{2,66}=1.059, P=0.35\right)$. Residents considered shading and beauty the most important tree services, whereas water use, root damage to sidewalks, and dropping debris were the most important tree disservices (Fig. 6). Height, ease of maintenance, and shading were the most important attributes reported by residents in selecting a tree to plant at their residence (Fig. 6). Of all respondents, 68\% had removed a tree from their property, with the most common reason being the tree was dead or diseased (Table 7). Eighty-three percent of respondents had a favorite tree in their yard, with maple trees (Acer) being the most common favorite genus. The most frequent reason given for a tree being a person's favorite was aesthetics or beauty (Table 7).

\section{Linking preferences to traits}

There were strong correlations between resident preferences for traits when choosing a tree to plant and the number of residential and nursery trees that had that trait (Fig. 6). There were also strong correlations between survey respondents' ratings of the importance of ecosystem services and disservices of trees with the number of residential and nursery trees that had desired traits (Fig. 6). Additionally, the favorite tree genus (Acer) was the most common genus found in nurseries and residential yards. Overall, we observed a strong relationship between resident favorite genus and number of nursery and yard trees in that genus (Fig. 7). The stated importance of fruit provision and the average fruit trait value in a yard were correlated, as was the desire for evergreen trees and the average evergreen trait value in the yard (Table 8). We found no other relationships for the other traits (Table 8).

\section{DisCUSSION}

We found broad support for our hypotheses that nursery offerings, resident preferences, and neighborhood characteristics shape patterns of urban tree diversity and composition in SLV in predicted ways. We focused on residential neighborhoods where most yard trees are planted by either homeowners or landscapers and street trees by homeowners or city managers. Most residents reported they bought their trees from local stores and the majority of species we inventoried in SLV neighborhoods were sold at local nurseries. Neighborhoods had different tree communities, both in terms of species composition and traits. Overall, we contend that the combination of resident preferences and nursery offerings provide a mechanism for the previously reported luxury effect as well as evidence for the ecology of prestige. For the luxury effect, we found large price differences and tree diversity differences between locally owned nurseries 

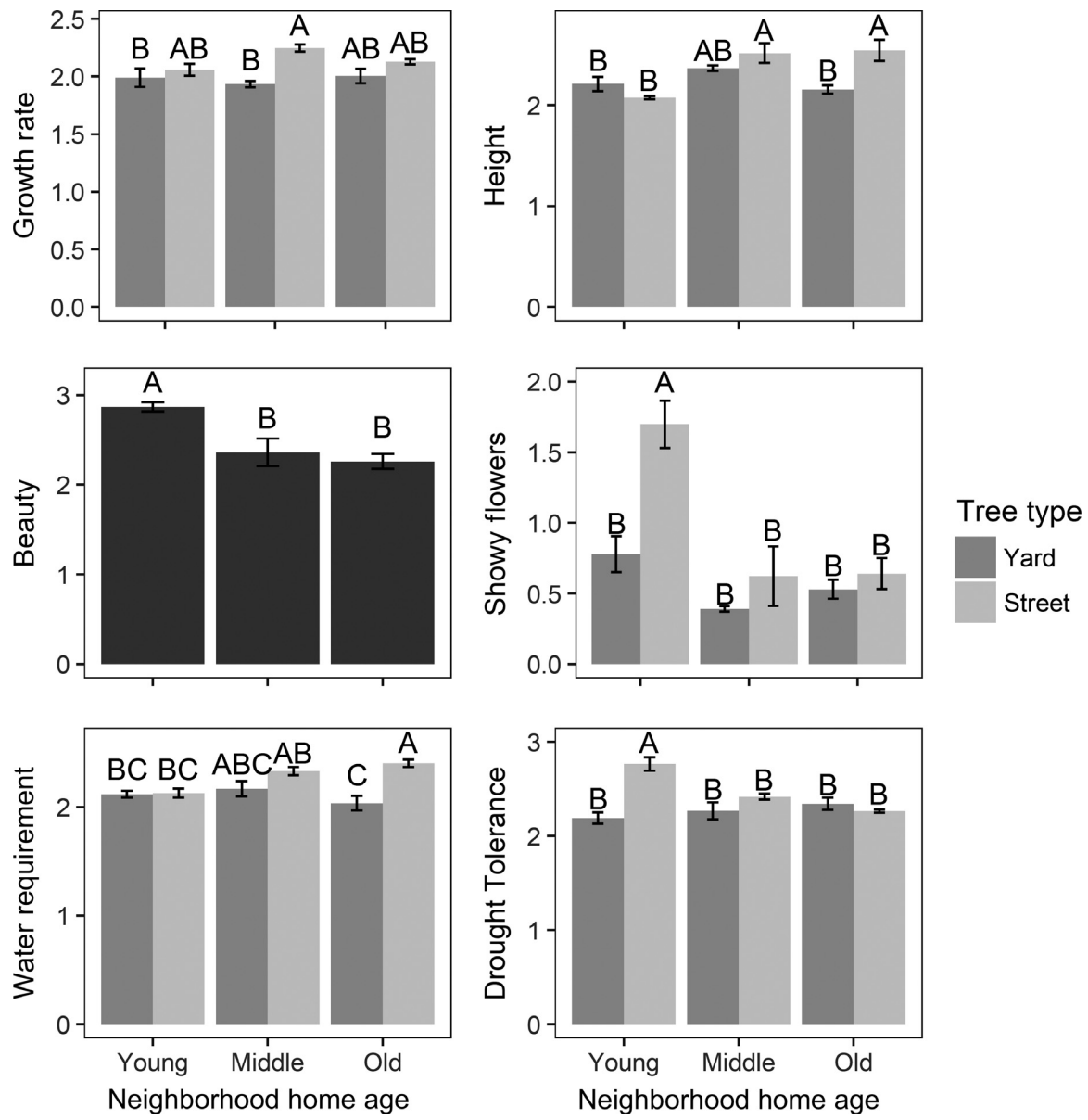

FIG. 5. Mean trait differences across tree location types (street and yard) and neighborhood home ages (young, middle, and old). Values are means \pm SE. Significant differences are denoted by letters as determined by Tukey-HSD with $P<0.05$. For beauty, there was no neighborhood age $\times$ tree type interaction, so only neighborhood age is shown (Table 5).

and mass merchandisers. If wealthier residents shop more often at locally owned nurseries, they are choosing species from a much larger species pool. For ecology of prestige, we found differences between neighborhoods in tree composition and traits, suggesting there are unique neighborhood aesthetics. Both of these social mechanisms contribute to tree biodiversity within cities.

Plant nurseries appear to be the main source of trees in SLV. This is not surprising since trees are not native to the valley floor, except in riparian areas (Whitney 1982, cited in Lowry et al. 2011). However, even in tropical cities, nurseries are the source of most residential plants (Torres-Camacho et al. 2016). As Thompson et al. (2003) and Pincetl et al. (2013) point out, plant nurseries serve as an enormous species pool for urban trees, though the linkages between the horticultural trade and urban tree community assembly is still understudied. Avolio et al. (unpublished manuscript) found that most of the trees inventoried in Los Angeles were also offered in local plant nursery catalogs, although that study simply relied on presence/absence of species. In this study, we found a strong relationship between the number of trees of a species for sale in retail nurseries and the number of trees of that same species found in neighborhoods. We also found a strong relationship between resident preferred tree genus and the most common genus sold at nurseries, as well as between resident tree trait preferences and the number of trees with those traits being sold. Most likely these relationships are driven by residents relying on local nursery stock and advice in tree selection as well as nurseries responding to customer preferences (Safley and Wohlgenant 1995, Hooper et al. 2008, Jin et al. 2013). However, these causal mechanisms warrant more research. We suggest that causal relationships in plant choice and nursery offerings are complex; there are dynamic interactions between nurseries and their range of customers that influence both nursery stock decisions and people's preferences for trees and tree traits. This decision-making process and the roles of different groups of buyers (e.g., residents, landscapers, city parks and maintenance departments) warrant greater attention in future research. Furthermore, we documented large differences in tree offerings between the mass merchandizers and locally owned nurseries, 
TABLE 6. Results of two-way ANOVAS of the effect of tree type (yard or street) and neighborhood home age (young, middle, or old) on the mean trait value of trees in a neighborhood.

\begin{tabular}{|c|c|c|c|}
\hline Trait & Tree type & Neighborhood home age & Tree type $\times$ Neighborhood home age \\
\hline Shading potential & $11.58(0.01)$ & $2.84(0.10)$ & $2.71(0.11)$ \\
\hline Fruit & $19.46(<0.01)$ & $0.08(0.92)$ & $0.07(0.93)$ \\
\hline Aroma & $2.58(0.13)$ & $1.53(0.26)$ & $5.51(0.02)$ \\
\hline Growth rate & $15.84(<0.01)$ & $3.78(0.05)$ & $6.74(0.01)$ \\
\hline Height & $5.71(0.03)$ & $9.49(<0.01)$ & $7.34(0.01)$ \\
\hline Longevity & $4.48(0.06)$ & $3.77(0.05)$ & $6.74(0.01)$ \\
\hline Power lines & $19.20(<0.01)$ & $1.57(0.25)$ & $1.29(0.31)$ \\
\hline Water requirement & $18.96(<0.01)$ & $3.45(0.07)$ & $6.91(0.01)$ \\
\hline Drought tolerance & $18.47(<0.01)$ & $4.45(0.04)$ & $13.87(<0.01)$ \\
\hline Native & $13.16(<0.01)$ & $2.60(0.12)$ & $0.86(0.45)$ \\
\hline Litter & $4.50(0.06)$ & $1.72(0.22)$ & $2.49(0.12)$ \\
\hline Root & $7.36(0.02)$ & $1.98(0.18)$ & $1.06(0.38)$ \\
\hline Poison & $7.45(0.02)$ & $1.95(0.18)$ & $1.63(0.24)$ \\
\hline Pests & $1.82(0.20)$ & $2.20(0.15)$ & $5.04(0.03)$ \\
\hline Allergen & $1.45(0.25)$ & $4.21(0.04)$ & $0.58(0.57)$ \\
\hline Bark & $4.82(0.05)$ & $0.61(0.56)$ & $2.83(0.10)$ \\
\hline Fall color & $10.07(0.01)$ & $2.10(0.16)$ & $1.57(0.25)$ \\
\hline Flowers & $14.90(<0.01)$ & $18.95(<0.01)$ & $5.40(0.02)$ \\
\hline Foliage & $18.28(<0.01)$ & $2.91(0.09)$ & $3.47(0.06)$ \\
\hline Fruit showy & $17.13(<0.01)$ & $1.78(0.21)$ & $2.37(0.14)$ \\
\hline Beauty & $0.01(0.93)$ & $8.67(<0.01)$ & $0.61(0.56)$ \\
\hline
\end{tabular}

Notes: $F$ values are shown with $P$ values in parentheses. Significant effects $(\mathrm{P}<0.05)$ are shown in boldface type. $F$-value degrees of freedom were 1,12 for tree type, 2,12 for neighborhood home age, and 2,12 for the interaction between tree type and neighborhood home age.

where locally owned nurseries offered 139 more tree species $(174 \%$ more) than mass merchandiser stores. This finding suggests that urban tree diversity is affected by residents' shopping behavior for horticultural products, as the species pools vary in size and composition by retail store type, as well as by the economic viability over time of different types of retail nursery stores.

Resident preferences were strongly correlated with traits of inventoried residential yard trees in SLV. Both environmental (e.g., temperature) and social factors (e.g., education and income) have been found to affect resident preferences for plant attributes (Avolio et al. 2015b, Larson et al. 2016). We found that provision of shade was important to residents, and shade (i.e., trees with large canopies) is a common trait of trees that are planted in SLV. Conversely, residents reported that provision of fruit was less important and there were considerably fewer fruit trees than shade trees in our yard tree inventories. Other studies have also found that resident preferences match the types of plants found in their yard (Marco and Barthelemy 2010, Kendal et al. 2012). Conversely, we found few significant relationships between a resident's preference and types of trees in their yard, which probably reflects the long-lived nature of trees where current tree composition of yards might more closely match the preferences of previous owners. Instead, when we scale up to the entire metropolitan area to consider tree diversity found across our entire study, resident preferences for tree traits were correlated with the distribution of those tree traits (Fig. 6). While we acknowledge that the self-reported preferences from residents do not necessarily correspond to behavior, this research emphasizes the need to better understand the factors driving plant choice decisions and their relationships to particular plant attributes in studies of urban plant diversity and ecosystem services.

Neighborhood characteristics, such as home age and income, interact to affect patterns of tree cover and diversity (Lowry et al. 2011, Clarke et al. 2013). We designed our study to be able to differentiate between these neighborhood characteristics by selecting neighborhoods where income and home age varied independently from one another. We found that neighborhood income was a strong predictor of urban yard tree structure, both in the number of trees and richness of trees, but did not explain patterns of street tree composition. Conversely, neighborhood home age explained patterns of street tree species richness, but not yard tree species richness. However, neighborhood age was a good predictor of density of number and density of species richness of yard trees. We also found that street and yard trees differed in species composition and traits. Previous studies have also found differences in traits of street and yard trees (Jim 1993, Avolio et al. 2015a). We found in newer neighborhoods, more street trees had showy flowers and were more drought tolerant compared with yard trees. This trend is strongly influenced by the dominance of flowering pear (Pyrus calleryana) in new neighborhoods, which on average accounted for $67 \%$ of all street trees in the new neighborhoods compared with $6 \%$ in old and middle-aged neighborhoods. This result is likely due to 

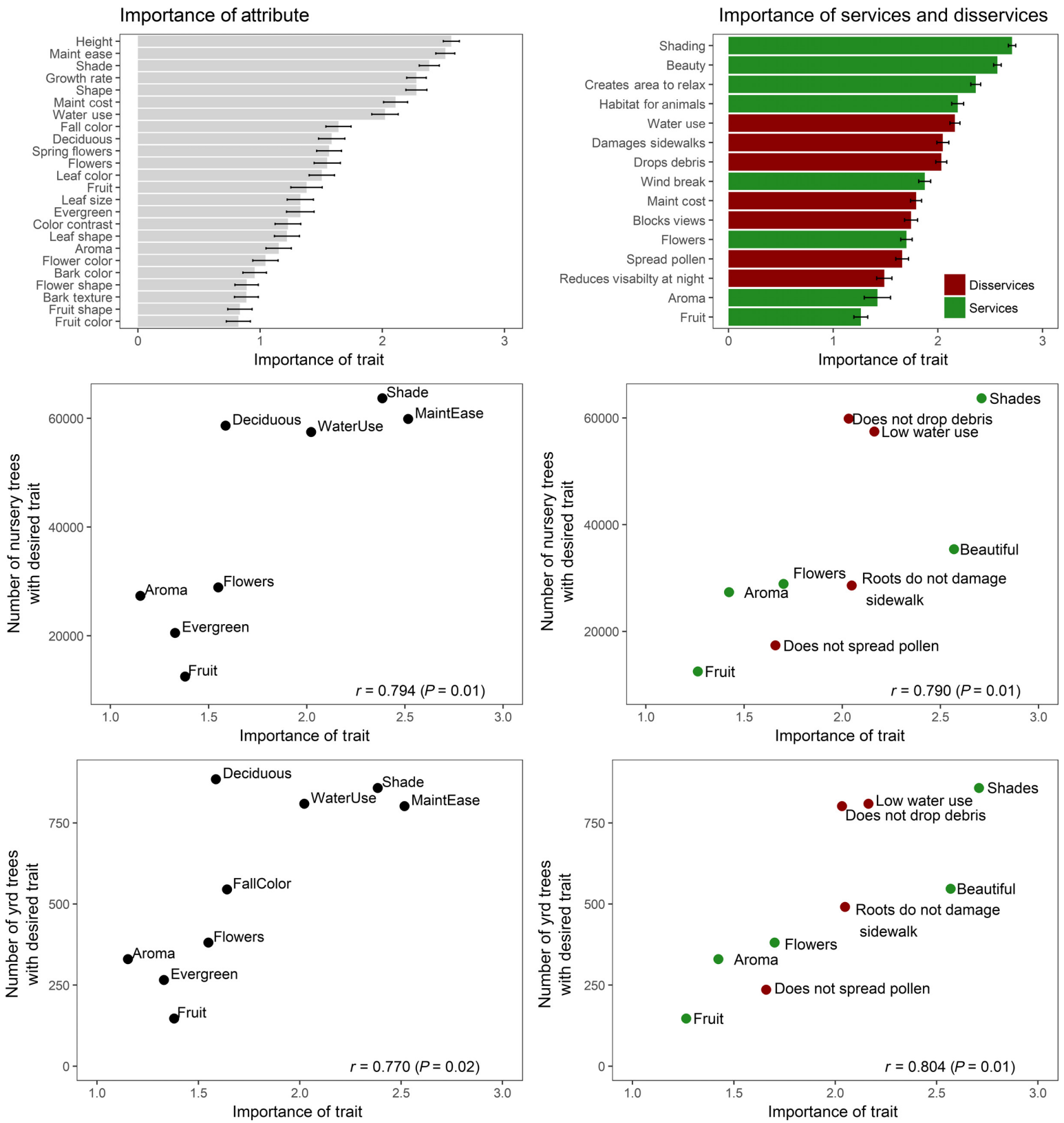

FIG. 6. Linking resident preferences with patterns of urban tree biodiversity. Top panel: the importance of tree attributes for residents when choosing a tree $(n=95)$ and ecosystem services and disservices provided by trees $(n=277)$. Bottom and middle panels: the relationship between resident preferences and the number of trees in nurseries (middle panel) and at residential yards (bottom panel) with the desired traits.

the popularity over several decades of flowering pear species that was promoted for its rapid growth, abundant spring flowering, and great fall color but that has fallen out of favor due to its shorter life span in the last few years. In fact, we found that street trees varied considerably in traits across the neighborhoods, while there was much less variation in the traits of yard trees. This finding suggests that residents are more similar to each other in their preferences for ecosystem services than public city tree managers or developers. We also think this behavior is indicative of the facts that the size and shape of locations where each group plants trees (yards vs. parking strips) and the tree traits that meet landscape objectives in each of those spaces differ. This research demonstrates the importance of distinguishing between trees on public (street) vs. private (yard) property, as well as identifying permissions, obligations, and guidelines for planting trees when assessing urban tree diversity. For example, up until recently many municipalities preferred to plant monocultures for aesthetic reasons 
TABle 7. Reasons residents either removed a tree from their yard (out of 189 responses), or a specific tree was their favorite (out of 225 responses).

\begin{tabular}{lc}
\hline \hline Reasons given... & Residents (\%) \\
\hline ..to remove a tree & \\
Died or diseased & 53 \\
Too big & 14 \\
Did not like species & 11 \\
Bad location in yard & 7 \\
Damage to property & 7 \\
High maintenance & 6 \\
Re-landscaped & 2 \\
Invasive & 1 \\
Attracted bugs & $<1$ \\
Too many trees & $<1$ \\
Not drought tolerant & $<1$ \\
for tree being favorite & \\
Aesthetics/Beauty & \\
Shade & 33 \\
Ease of maintenance & 19 \\
Size & 8 \\
Shape & 8 \\
Fruit & 5 \\
Personal reasons (memories, etc.) & 5 \\
Attracts wildlife & 5 \\
Local history/Age of tree & 3 \\
Unique & 2 \\
Yard landscaping/Placement & 3 \\
Fast growth & 2 \\
Leaves in wind (sound, look) & 2 \\
Privacy & 2 \\
Aroma & 2 \\
Native & 1 \\
Low water use & 1 \\
Evergreen & 2 \\
Reminds of mountains & 1 \\
Place to play & 2 \\
Species-specific attributes & 2 \\
\hline
\end{tabular}

(Santamour 1990, McPherson et al. 2016) but now prefer more diverse tree assemblages.

Although the luxury effect has been observed in many cities, i.e., higher income areas have more plant species (Hope et al. 2003, Martin et al. 2004, Avolio et al. 2015a), the mechanisms that account for this relationship remain unclear. Hope et al. (2003) suggested that either wealthier people move to neighborhoods with high plant diversity or that high income allows residents to create high plant diversity. Our study was uniquely designed to study income without other confounding factors, as we chose neighborhoods with similar environmental conditions and neighborhood characteristics. Here, we suggest that residents in higher income neighborhoods create more diverse yards. More affluent residents have been found to purchase plants from more expensive, locally owned or traditional nursery stores with greater nursery stock variety than from national chain stores with more limited plant choices (Turner and Dorfman 1990, Day
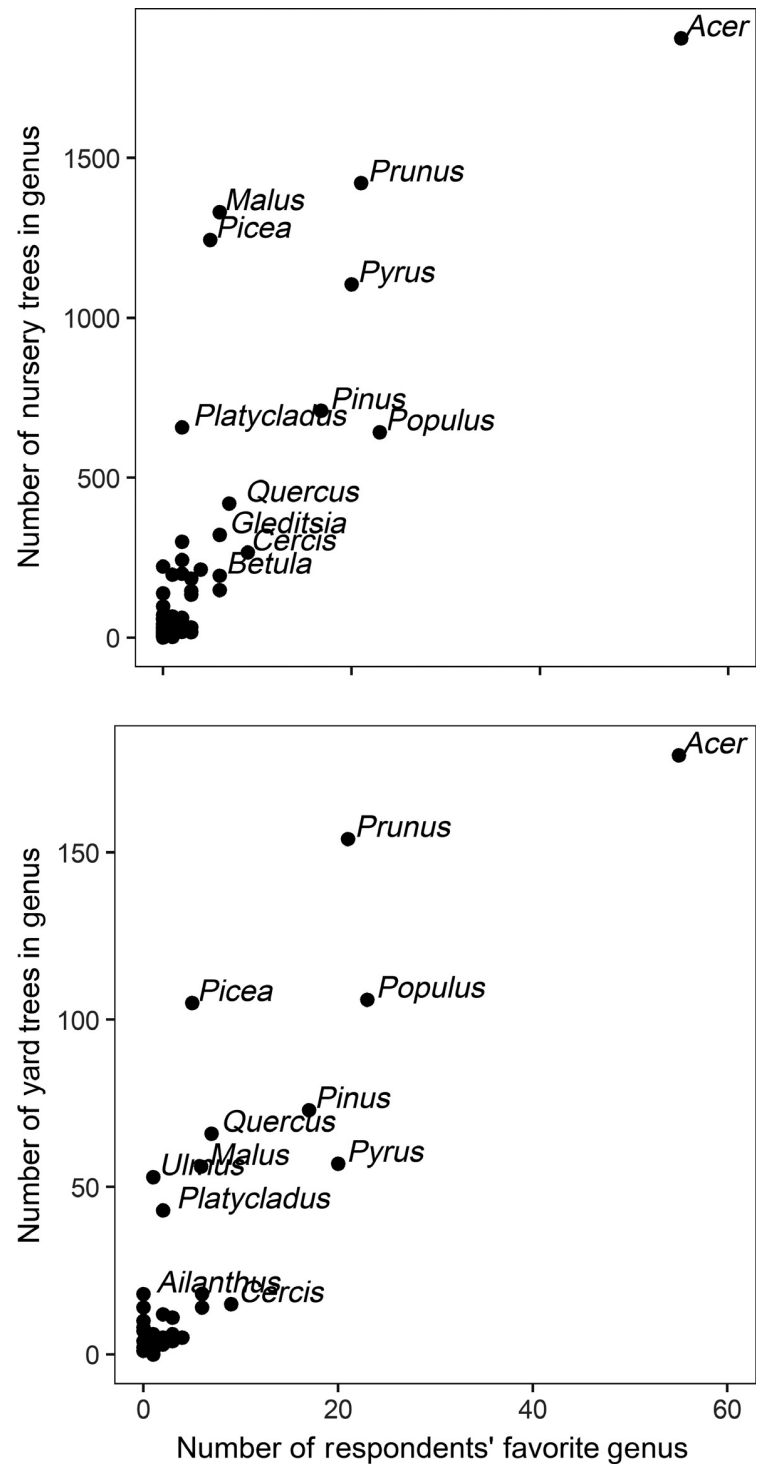

FIG. 7. Relationship between residents' favorite genus and the number of species in that genus found in yards $(r=0.852$; $P=<0.001)$ and offered in local nurseries $(r=0.814, P<0.001)$.

TABLE 8. Correlations between the ranked importance of traits that residents stated as criteria for selecting trees for their yard, and the average trait value of trees in their yard.

\begin{tabular}{lcc}
\hline \hline Trait & Relationship & \\
& $r$ & $P$ \\
\hline Shading & 0.068 & 0.533 \\
Provision of fruit & $\mathbf{0 . 2 2 3}$ & $\mathbf{0 . 0 3 8}$ \\
Water use & -0.205 & 0.058 \\
Deciduous & -0.149 & 0.179 \\
Evergreen & $\mathbf{0 . 2 6 6}$ & $\mathbf{0 . 0 1 4}$ \\
Flowers & 0.016 & 0.881 \\
Aroma & 0.124 & 0.251 \\
Ease of maintenance & 0.008 & 0.939 \\
Fall color & 0.052 & 0.635
\end{tabular}

Notes: Significant effects $(P<0.05)$ are shown in boldface type. 
1994, Hudson et al. 1997, Yue and Behe 2008, Jin et al. 2013); our data support this finding. When shopping at locally owned nurseries, residents paid more for a tree, and chose from a much wider range of species. By selecting and purchasing plants from a larger source pool, higher income areas had a greater species variety to draw from compared with low income neighborhoods. Both yard area and number of trees were also greater in higher income areas, suggesting the yard conditions in those neighborhoods provided more space to support a greater range of tree plantings. We found that the median parcel area of a neighborhood was not related to the number or the richness of trees, but we did observe a positive relationship between the number of trees and tree species richness $(r=0.899, P<0.001)$. Thus, it is unclear if higher species richness is simply an artifact of there being more trees in wealthier neighborhoods. van Heezik et al. (2014) also found a positive relationship between income and vegetated yard area with woody species richness, demonstrating the difficulty of teasing apart these relationships.

The theory of the ecology of prestige (Grove et al. 2006,2014 ) hypothesizes that yard vegetation provides a means for residents to display social status and collectively uphold neighborhood identity (Grove et al. 2014). Many studies have found differences in plant cover and species richness across neighborhoods of varying social characteristics such as income (Iverson and Cook 2000, Kinzig et al. 2005, Cook et al. 2012). Here, we went further and assessed differences in the composition of species and their associated traits across nine neighborhoods that vary in home age and income. We found that tree communities are more homogenous within a neighborhood than they are between neighborhoods, both in terms of composition and traits of species, demonstrating that neighborhoods have different tree communities. Cultural norms about acceptable and desirable plant species have been found to affect resident preferences for yard vegetation and aesthetics (Andersson et al. 2007, Nassauer et al. 2009, Kurz and Baudains 2010, Marco and Barthelemy 2010). Zmyslony and Gagnon (1998) found that yards that were nearer to one another had more similar vegetation structure; similarly, we found neighborhoods that were closer to one another had more similar tree communities. Our results further support that neighborhoods have their own landscape identities (related to a combination of characteristics of residential yards, time of development, and occupants) that are expressed in the composition of tree species and their associated traits. These landscape identities likely contribute to the role that trees have in creating a sense of place (Dwyer et al. 1991, Stedman 2003, Pearce et al. 2015) whereby people form a bond with specific trees and with the attributes of a place that trees help create. The role that people's attachments to certain trees and places within the urban environment have in their future home purchasing decisions or planting choices deserves further research.

\section{Conclusions}

This research has broad implications for management of ecosystem services and disservices in cities, with a focus on cultural services over regulating ecosystem services (Bennett et al. 2009). Nassauer et al. (2009) suggested that changing resident landscape preferences and behaviors will be an important part of realizing more sustainable cities. Notably, ecologists have long sought to provide relevant information about species that are environmentally suitable for given locations and that contribute to biodiversity in urban environments. However, we suggest that when these recommendations do not take into account the preferences of residents for key plant attributes (such as shade provision) and plant availability through the nursery industry, these efforts may not be successful. Because large trees are not native to SLV beyond the riparian corridor, it is challenging to develop appropriate scientific information and recommendations for maintaining a biologically diverse and resource use-efficient tree species pool in this and other semiarid regions where water availability is of increasing concern (Hale et al. 2015). One of the ways ecologists can inform future landscaping decisions is by bridging the information gap between traits that are classified as contributing primarily to cultural services and traits that also contribute to regulating services, and which trees can contribute both types of services. As concerns over sustainability increasingly influence urban design, we think that the nursery industry and its customers will become more receptive to and eager for this information. Our approach provides an avenue to quantify traits associated with both ecosystem services (e.g., provision of shade, goods, and beauty) as well as disservices (e.g., tree water use, damage to sidewalks), which can be applied toward designing and planning urban spaces that meet both social and environmental criteria. In this way, ecologists can work with urban planners, landscape designers, local nurseries, and the public to develop strategies that maximize ecosystem services while minimizing ecosystem disservices provided by trees in public and private urban spaces in any city where trees are planted.

\section{ACKNOWLEDGMENTS}

We thank La'Shaye Ervin Cobley, Moumita Kundu, and Claire O'Donnell for their help with field data collection, Zacharia Levine for his assistance with administering the surveys, and Barbara Uhl for entering the mail and yard survey answers. We also thank two anonymous reviewers for their thoughtful comments. This research was supported by NSF EPSCoR Grant EPS 1208732 awarded to Utah State University and the University of Utah, as part of the iUTAH project funded by this State of Utah Research Infrastructure Improvement Award. M. L. Avolio was also supported by the National Socio-Environmental Synthesis Center (SESYNC) NSF DBI1052875. All authors assisted in designing the study and editing the paper. M. L. Avolio and T. L. E. Trammell performed the research and M. L. Avolio analyzed the data and wrote the paper. 


\section{Literature Cited}

Anderson, K. 2007. Temporal patterns in rates of community change during succession. American Naturalist 169:780-793.

Andersson, E., S. Barthel, and K. Ahrné. 2007. Measuring social-ecological dynamics behind the generation of ecosystem services. Ecological Applications 17:1267-1278.

Avolio, M. L., D. E. Pataki, T. W. Gillespie, G. D. Jenerette, H. R. McCarthy, S. Pincetl, and L. Weller Clarke. 2015a. Tree diversity in southern California's urban forest: the interacting roles of social and environmental variables. Frontiers in Ecology and Evolution 3:1-15.

Avolio, M. L., D. E. Pataki, S. Pincetl, T. W. Gillespie, G. D. Jenerette, and H. R. McCarthy. 2015b. Understanding preferences for tree attributes: the relative effects of socio-economic and local environmental factors. Urban Ecosystems 18:73-86.

Bennett, E. M., G. D. Peterson, and L. J. Gordon. 2009. Understanding relationships among multiple ecosystem services. Ecology Letters 12:1394-1404.

Bourne, K. S., and T. M. Conway. 2013. The influence of land use type and municipal context on urban tree species diversity. Urban Ecosystems 17:329-348.

Brenzel, K. N., (Ed.) 2001. Western garden book. Sunset Publishing Corp., Menlo Park, California, USA.

Clarke, L. W., G. D. Jenerette, and A. Davila. 2013. The luxury of vegetation and the legacy of tree biodiversity in Los Angeles, CA. Landscape and Urban Planning 116:48-59.

Conway, T. M., and J. Vander Vecht. 2015. Growing a diverse urban forest: species selection decisions by practitioners planting and supplying trees. Landscape and Urban Planning 138:1-10.

Cook, E. M., S. J. Hall, and K. L. Larson. 2012. Residential landscapes as social-ecological systems: a synthesis of multiscalar interactions between people and their home environment. Urban Ecosystems 15:19-52.

Daly, C., M. P. Widrlechner, M. D. Halbleib, J. I. Smith, and W. P. Gibson. 2012. Development of a new USDA plant hardiness zone map for the United States. Journal of Applied Meteorology and Climatology 51:242-264.

Day, E. 1994. An exploratory study of garden center selection for landscape plants. Journal of Environmental Horticulture 12:142-146.

Dwyer, J. F., D. J. Nowak, M. H. Noble, and S. M. Sisinni. 2000. Connecting people with ecosystems in the 21st century: an assessment of our nation's urban forests. General Technical Report PNW-GTR-490. U.S. Department of Agriculture, Forest Service, Portland Oregon, US.

Dwyer, J. F., H. W. Schroeder, and P. H. Gobster. 1991. The significance of urban trees and forests: toward a deeper understanding of values. Journal of Arboriculture 17:276-284.

Groemping, U., and L. Matthias. 2013. relaimp: Relative importance of regressors in linear models. R package version 2.2-2.

Grove, J. M., D. H. Locke, and J. P. M. O’Neil-Dunne. 2014. An ecology of prestige in New York City: examining the relationships among population density, socio-economic status, group identity, and residential canopy cover. Environmental Management 54:402-419.

Grove, J. M., A. R. Troy, J. P. M. O’Neil-Dunne, W. R. Burch, M. L. Cadenasso, and S. T. A. Pickett. 2006. Characterization of households and its implications for the vegetation of urban ecosystems. Ecosystems 9:578-597.

Hale, R. L., et al. 2015. iSAW: integrating structure, actors, and water to study socio-hydro-ecological systems. Earth's Future $3: 110-123$.

Hall, C. R., A. W. Hodges, and M. A. Palma. 2011. Sales, trade flows and marketing practices within the US nursery industry. Journal of Environmental Horticulture 29:14-24.
Hijmans, R. J., E. Williams, and C. Vennes. 2017. geosphere: spherical trigonometry. R package version 1.5-7.

Hooper, V. H., J. Endter-Wada, and C. W. Johnson. 2008. Theory and practice related to native plants: a case study of Utah landscape professionals. Landscape Journal 27:127-141.

Hope, D., C. Gries, W. Zhu, W. F. Fagan, C. L. Redman, N. B. Grimm, A. L. Nelson, C. Martin, and A. Kinzig. 2003. Socioeconomics drive urban plant diversity. Proceedings of the National Academy of Sciences USA 100:8788-8792.

Hudson, J. T., B. K. Behe, H. G. Ponde, and W. E. Barrick. 1997. Consumer perceptions and expectations of garden center product and service quality. Journal of Environmental Horticulture 15:12-15.

Hundley, N. Jr. 2001. The great thirst: Californians and water a history. Revised edition. University of California Press, Berkeley, California, USA.

Iverson, L., and E. Cook. 2000. Urban forest cover of the Chicago region and its relation to household density and income. Urban Ecosystems 4:105-124.

Jackson-Smith, D., P. Stoker, M. Buchert, J. Endter-Wada, C. Licon, M. Cannon, and S. Li. 2016. Differentiating urban forms: a neighborhood typology for understanding urban water systems. Cities and the Environment (CATE) 9:art 5.

Jenerette, G. D., et al. 2016. Climate tolerances and trait choices shape continental patterns of urban tree biodiversity. Global Ecology and Biogeography 25:1367-1376.

Jim, C. Y. 1993. Trees and landscape of a suburban residential neighbourhood in Hong Kong. Landscape and Urban Planning 23:119-143.

Jin, L., M. K. Wohlgenant, C. D. Safley, N. Carolina, and N. Reynolds. 2013. Impact of income and different generation cohorts on nursery products and landscaping project spending. Impact of Income and Different Generation 45:65-77.

Kahrl, W. L. 1983. Water and power: the conflict over Los Angeles water supply in the Owens Valley. University of California Press, Berkeley, California, USA.

Kendal, D., K. J. H. Williams, and N. S. G. Williams. 2012. Plant traits link people's plant preferences to the composition of their gardens. Landscape and Urban Planning 105: $34-42$.

Kinzig, A. A. P., P. S. Warren, C. Martin, D. Hope, and M. Katti. 2005. The effects of human socioeconomic status and cultural characteristics on urban patterns of biodiversity. Ecology and Society 10:art23.

Kurz, T., and C. Baudains. 2010. Biodiversity in the front yard: an investigation of landscape preference in a domestic urban context. Environment and Behavior 44:166-196.

Larson, K. L., et al. 2016. Ecosystem services in managing residential landscapes: priorities, value dimensions, and crossregional patterns. Urban Ecosystems 19:95-113.

Lowry, J. H., M. E. Baker, and R. D. Ramsey. 2011. Determinants of urban tree canopy in residential neighborhoods: household characteristics, urban form, and the geophysical landscape. Urban Ecosystems 15:247-266.

Marco, A., and C. Barthelemy. 2010. Bridging human and natural sciences for a better understanding of urban floral patterns: the role of planting practices in Mediterranean gardens. Ecology and Society 15:art2.

Martin, C. A., P. S. Warren, and A. P. Kinzig. 2004. Neighborhood socioeconomic status is a useful predictor of perennial landscape vegetation in residential neighborhoods and embedded small parks of Phoenix, AZ. Landscape and Urban Planning 69:355-368.

McPherson, E. G., N. van Doorn, and J. de Goede. 2016. Structure, function and value of street trees in California, USA. Urban Forestry \& Urban Greening 17:104-115. 
Nassauer, J. I., Z. Wang, and E. Dayrell. 2009. What will the neighbors think? Cultural norms and ecological design. Landscape and Urban Planning 92:282-292.

Nowak, D. J. 2012. Contrasting natural regeneration and tree planting in fourteen North American cities. Urban Forestry \& Urban Greening 11:374-382.

Oksanen, J., F. G. Blanchet, R. Kindt, P. Legendre, P. R Minchin, R. B. O’Hara, G. L. Simpson, P. Solymos, H. H. Stevens, and H. Wagner. 2017. vegan: Community Ecology Package. R package version 2.4-5.

Pataki, D., H. McCarthy, T. Gillespie, G. Jenerette, and S. Pincetl. 2013. A trait-based ecology of the Los Angeles urban forest. Ecosphere 4:1-20.

Pearce, L. M., A. Davison, and J. B. Kirkpatrick. 2015. Personal encounters with trees: the lived significance of the private urban forest. Urban Forestry \& Urban Greening $14: 1-7$.

Pincetl, S., S. S. Prabhu, T. W. Gillespie, G. D. Jenerette, and D. E. Pataki. 2013. The evolution of tree nursery offerings in Los Angeles County over the last 110 years. Landscape and Urban Planning 118:10-17.

Ripley, B., B. Venables, D. M. Bates, K. Hornik, A. Gebhardt, and D. Firth. 2017. MASS. R package version 7.3-48.

Safley, C., and M. Wohlgenant. 1995. Factors influencing consumers' selection of garden centers. Journal of Agribusiness 13:33-50.

Santamour, F. S. 1990. Trees for urban planting: diversity, uniformity and common sense. Pages 57-65 in Proceedings, 7th Conference Metropolitan Tree Improvement Alliance (METRIA). Metria, Lisle, Illinois, USA.

Shakeel, T., and T. M. Conway. 2014. Individual households and their trees: fine-scale characteristics shaping urban forests. Urban Forestry \& Urban Greening 13: $136-144$.

Stedman, R. 2003. Is it really just a social construction?: the contribution of the physical environment to sense of place. Society \& Natural Resources 16:671-685.
Thompson, K., K. C. Austin, R. M. Smith, P. H. Warren, P. G. Angold, and K. J. Gaston. 2003. Urban domestic gardens (I): putting small-scale plant diversity in context. Journal of Vegetation Science 14:71-78.

Torres-Camacho, K. A., E. J. Meléndez-Ackerman, E. Diaz, N. Correa, C. Vila-Ruiz, S. Olivero-Lora, A. Erazo, J. Fontánez, L. Santiago, and J. Seguinot. 2016. Intrinsic and extrinsic drivers of yards vegetation in urban residential areas: implications for conservation planning. Urban Ecosystems. https://doi.org/10.1007/s11252-016-0602-9

Townsley-Brascamp, W., and N. Marr. 1995. Evaluation and analysis of consumer preferences for outdoor ornamental plants. Acta Horticulturae 391:199-208.

Turner, S. C., and J. H. Dorfman. 1990. Retail target markets for landscape plants. Journal of Environmental Horticulture $8: 115-118$.

U.S. Census Bureau. 2010. Annual estimates of the population of metropolitan and micropolitan statistical areas. Population Estimates, Population Division.

van Heezik, Y. M., C. Freeman, S. Porter, and K. J. M. Dickinson. 2014. Native and exotic woody vegetation communities in domestic gardens in relation to social and environmental factors. Ecology and Society 19:17.

Yue, C., and B. K. Behe. 2008. Estimating U.S. consumers' choice of floral retail outlets. HortScience 43:764-769.

Yue, C., and B. K. Behe. 2009. Factors affecting U.S. consumer patronage of garden centers and mass-merchandisers. Acta Horticulturae 831:301-308.

Zhang, H., and C. Y. Jim. 2014. Species diversity and performance assessment of trees in domestic gardens. Landscape and Urban Planning 128:23-34.

Zipperer, W. C., S. S. Sisinni, R. R. Pouyat, and T. T. Foresman. 1997. Urban tree cover: an ecological perspective. Urban Ecosystems 1:229-246.

Zmyslony, J., and D. Gagnon. 1998. Residential management of urban front-yard landscape: A random process? Landscape and Urban Planning 40:295-307.

\section{SUPPORTING INFORMATION}

Additional supporting information may be found online at: http://onlinelibrary.wiley.com/doi/10.1002/ecm.1290/full

Data Availability

Data associated with this study are available from the Dryad Digital Repository: https://doi.org/10.5061/dryad.70d46 